\title{
BMJ Open Quantifying conflict zones as a challenge to certification of Guinea worm eradication in Africa: a new analytical approach
}

\author{
Louise A Kelly-Hope (D) ,1,2 David H Molyneux ${ }^{2}$
}

To cite: Kelly-Hope LA, Molyneux DH. Quantifying conflict zones as a challenge to certification of Guinea worm eradication in Africa: a new analytical approach. BMJ Open 2021;11:e049732. doi:10.1136/ bmjopen-2021-049732

- Prepublication history and additional supplemental material for this paper are available online. To view these files, please visit the journal online. (http://dx.doi.org/10.1136/ bmjopen-2021-049732)

Received 01 February 2021 Accepted 20 July 2021

A) Check for updates

(C) Author(s) (or their employer(s)) 2021. Re-use permitted under CC BY-NC. No commercial re-use. See rights and permissions. Published by BMJ.

${ }^{1}$ Department of Livestock and One Health, Institute of Infection, Veterinary \& Ecological Sciences, University of Liverpool, Liverpool, UK

${ }^{2}$ Tropical Disease Biology, Liverpool School of Tropical Medicine, Liverpool, UK

Correspondence to Dr Louise A Kelly-Hope; L.Kelly-Hope@liverpool.ac.uk

\section{ABSTRACT}

Objectives To quantify conflict events and access across countries that remain to be certified free of transmission of Dracunculus medinensis (Guinea worm disease) or require postcertification surveillance as part of the Guinea Worm Eradication Programme (GWEP).

Setting and participants Populations living in Guinea worm affected areas across seven precertification countries and 13 postcertification sub-Saharan African countries.

Outcome measures The number of conflict events and rates per 100000 population, the main types of conflict and actors reported to be responsible for events were summarised and mapped across all countries. Chad and Mali were presented as case studies. Guinea worm information was based on GWEP reports. Conflict data were obtained from the Armed Conflict Location and Event Data Project. Maps were created using ArcGIS V.10.7 and access was measured as regional distance and time to cities.

Results More than 980000 conflict events were reported between 2000 and 2020, with a significant increase since 2018. The highest number and rates were reported in precertification Mali $(n=2556 ; 13.0$ per 100000$)$, South Sudan ( $n=2143 ; 19.4)$, Democratic Republic of Congo $(n=7016 ; 8.1)$ and postcertification Nigeria $(n=6903$; 3.4), Central Africa Republic ( $n=1251 ; 26.4$ ), Burkina Faso $(n=2004 ; 9.7)$. Violence against civilians, protests and battles were most frequently reported with several different actors involved including Unidentified Armed Groups and Boko Haram. Chad and Mali had contracting epidemiological and conflict situations with affected regions up to $700 \mathrm{~km}$ from the capital or 10 hours to the nearest city.

Conclusions Understanding the spatial-temporal patterns of conflict events, identifying hotspots, the actors responsible and their sphere of influence is critical for the GWEP and other public health programmes to develop practical risk assessments, deliver essential health interventions, implement innovative surveillance, determine certification and meet the goals of eradication.

\section{INTRODUCTION}

Guinea worm or dracunculiasis is one of two infections that have been designated formally by the World Health Assembly as
Strengths and limitations of this study

- This study is the first to analyse the impact, extent and challenges facing the Guinea Worm Eradication Programme as a result of increased conflict in subSaharan Africa.

- The methodology employed is based on conflict data downloaded from the Armed Conflict Location and Event Data Project using georeferenced location data on conflict event types.

- This real-time data can be used by both endemic countries and international organisations for planning programmatic activities for risk assessment purposes for surveillance and certification planning.

- Such data will inform the time scale for Guinea Worm Certification missions given that access to and information from areas where risk of conflict exists will require innovative approaches to acquire robust epidemiological data as a prerequisite for certification of absence of transmission in a country.

diseases targeted for eradication, the other being poliomyelitis. ${ }^{1-3}$ Yaws eradication has also been included as a target in the recently approved WHO Neglected Tropical Disease (NTD) Road Map 2021-2030. ${ }^{4}$ Eradication requires Certification of each member state of the United Nations as being free of transmission of the infectious agent Dracunculus medinensis. The Guinea Worm Eradication Programme (GWEP) has more recently adopted specific definitions approved by the International Commission for the Certification of Dracunculiasis Eradication (ICCDE), which reflect the criteria required to confirm the elimination from a country and following that the need for all countries to be free of transmission prior to Global Certification of Eradication by the World Health Assembly. ${ }^{2}$

Elimination of dracunculiasis is the confirmed absence of the emergence of adult female worms (the interruption of transmission of D. medinensis) in humans 
and animals for three consecutive years or longer from a country with such a low risk of reintroduction of the parasite that preventive measures could be reduced to a strict minimum. Worldwide eradication of dracunculiasis is the confirmed absence of the emergence of adult female worms (defined as compatible with the interruption of transmission of D. medinensis) in humans and animals for 3 years or longer at the global level. ${ }^{2}$

Recently, the challenges of certifying elimination in countries and then eradication globally have been highlighted. ${ }^{56}$ While the numbers of human cases have declined by over $99 \%$ since the programme began in the late $1980 \mathrm{~s}^{7}$ from an estimated 3 million cases per year to some 27 cases reported to date in $2020,{ }^{389}$ the problems of animal infections, in particular in dogs, has arisen and in Chad new modes of transmission have been uncovered involving paratenic hosts in fish, predominantly small 'fingerlings'. ${ }^{10-13}$ While Chad is the most serious challenge to global eradication given the high numbers of dogs reported infected annually (over 1900 in 2019 and 1500 in 2020), ${ }^{1415}$ dogs have been found infected consistently, although in small numbers in Mali, Ethiopia and Angola. ${ }^{23}$ The problems of insecurity have been a continuing part of the GWEP for as long ago as 1995 when President Jimmy Carter personally negotiated a 'Guinea Worm ceasefire' in South Sudan to enable all programme activities to recommence, ${ }^{16}$ while Mali has experienced heightened insecurity over recent years making access to some endemic areas difficult. ${ }^{17}$ In early 2021 the death of the President of Chad has destabilised the regime and some GWEP Chad programme staff have been evacuated from the country). ${ }^{3}$

While the challenge of animal infections is a recent phenomenon, all countries previously certified have not reported any animal infections despite surveillance in formerly endemic areas. ${ }^{15}$ However, a significant further challenge is the problem of access to insecure areas due to conflict and violence. ${ }^{561518}$ Five endemic countries require to be certified together with the Democratic Republic of Congo (DRC) and Sudan, while not currently endemic, having not reported a human case since 1958 and 2002 respectively, require to be verified as free of transmission based on a visit from an International Certification Team (ICT). If access due to insecurity and conflict is curtailed or limited given the onus on any ICT is to 'prove a negative' as far as is possible would be impaired and would limit the validity of any report which recommended that the country was free of transmission. 'Proving a negative' is not possible in any public health or scientific endeavour hence the ICT missions have to balance judgements made on the basis of available information and data supplied by the country.

At present there is no standardised approach to evaluate the level of conflict risk in Guinea worm endemic countries which cover vast areas of Africa. This is critical, as conflict significantly disrupts the implementation of health service delivery, impact assessments, research and surveillance. ${ }^{19-22}$ In this paper, we present an approach to quantifying the risks in countries yet to be certified, as well as those already certified but require continuing surveillance until global eradication has been declared. Since elimination of transmission was confirmed by the ICCDE in some 13 countries in Africa, the security situation has changed. Civil unrest and insecurity will have impacted on the ability of countries to maintain a level of surveillance compatible with adequate postcertification scrutiny. This applies, in particular to Sahelian countries, where jihadist movements control large swathes of some countries and where national authorities have limited access or control. This is exemplified in Niger, Burkina Faso, Nigeria, Senegal, Mauritania and Cameroon whereas in Central African Republic (CAR) inter religious conflict prevents access to the area bordering Chad..$^{23}{ }^{24}$ In the DRC there is significant conflict in eastern regions of the country and the border of South Sudan and Sudan has a high level of insecurity.

To address this challenge, we examined the number of conflict events from 2000 to 2020 to highlight long-term temporal trends in countries (1) previously certified as free of transmission, (2) currently endemic (precertification countries) and (3) requiring certification but which have not recorded a case of the infection since the inception of the GWEP in the late 1980s. We quantified the number of conflict events and rates per 100000 population for the most recent years, highlight the main types of conflict and the main actors responsible, as well as present specific data from Chad and Mali as case studies.

\section{METHODS}

\section{Study area}

The cross-sectional study included sub-Saharan African countries that were categorised as those in the precertification stage and those in the postcertification stage.

Precertification countries included those currently endemic for dracunculiasis, namely Angola, Chad, Ethiopia, Mali and South Sudan (from 2011 Independence onwards), and countries with historical evidence of Guinea worm but are yet to been certified as free from dracunculiasis, including the DRC and Sudan.

Postcertification countries included Benin, Burkina Faso, Cameroon, CAR, Cote d'Ivoire, Ghana, Kenya, Mauritania, Niger, Nigeria, Senegal, Togo and Uganda. The dates when these countries were certified free of transmission are provided in Molyneux et al. ${ }^{5}$ See figure 1 for the map of precertification and postcertification countries which cover vast geographical regions of subSaharan Africa covering more than 15 million square kilometres $\left(\mathrm{km}^{2}\right)^{25}$ with poor accessibility to urban centres or cities. ${ }^{26}$ The land area of each country is shown in table 1 with Angola, Chad, DRC, Mali, Niger and Sudan more than 1.2 million $\mathrm{km}^{2}$ in size. 


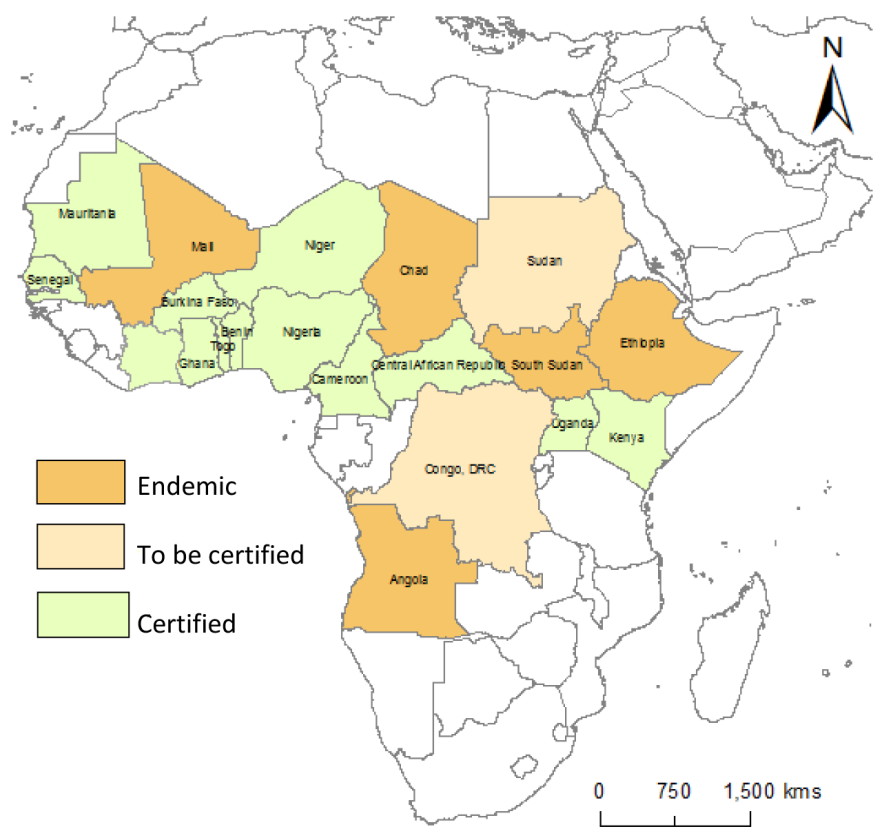

Figure 1 Map of precertification and certified countries in sub-Saharan Africa. DRC, Democratic Republic of Congo.

\section{Data sources}

To examine Guinea worm status in relation to spatial and temporal distribution of conflict events and regional access within each country, several data sources were obtained:

- Guinea worm information was based on WHO annual reports and Dracunculiasis Eradication Portal, ${ }^{21527}$ and GWEP reports by The Carter Centre and the Centres for Disease Control and Prevention. ${ }^{38}$

- Conflict data were downloaded from the Armed Conflict Location and Event Data Project (ACLED), ${ }^{28} 29$ including georeferenced location data on conflict event types categorised as battles, riots, protests, strategic developments, explosions/remote violence and violence against civilians and actors, that is, groups of people or organisations reported to be responsible for the events (definitions available on ACLED website) $)^{29}$ for the period from January 2000 to October 2020.

- Population data were obtained from the World Bank databank and based on 2019 estimates. ${ }^{25}$

- Administrative boundary information was obtained from the United Nations Office for the Coordination of Humanitarian Affairs. ${ }^{30}$

- Accessibility information was based on regional distance (kilometres $(\mathrm{kms}))$ to the capital city and from modelled maps of 'Accessibility to cities', quantified as travel time in minutes (converted to hours) to the nearest high-density urban centre or city at a resolution of $1 \times 1 \mathrm{~km}$ for 2015 . $^{26}$

These data sources represent the best available in the public domain, and it is acknowledged that there may be some missing cases and conflict event data, and differences in population estimates, country size and accessibility compared with other sources.

Patient and public involvement

No patient was included in this study.

\section{Data analysis and mapping}

Conflict and population data were downloaded, and collated, tabulated and graphed in Microsoft Excel (Microsoft, Redmond, Washington, USA) and the administrative boundary and accessibility to cities data were downloaded and imported into geographical information software (GIS) ArcGIS V.10.7 (ESRI, Redlands, California, USA) for mapping using the available GPS coordinates and descriptive analysis.

First, the number of conflict events for the precertification and postcertification countries were summarised for years from 2000 to 2020 to highlight long-term temporal trends and high-conflict Guinea worm countries.

Second, the overall number of conflict events and rates per 100000 population for the most recent years, 20182020, were quantified for each country. The different types of conflict events were tabulated and mapped, and the countries with the most events and highest rates per population were identified as high-conflict countries. The main actors reported to be responsible for the highest number of events in the high-conflict countries were summarised.

Finally, the situation in Chad and Mali since 2018 was presented as contrasting case studies, and included a summary and maps of the number of Guinea worm human and/or animal cases and regions affected; the number of conflict events types and main actors in each region; and accessibility of each region measured as the distance $(\mathrm{kms})$ between the centre of each region and each capital city using the Measure tool in ArcGIS, and the average time (hours) of each region to high-density urban centre or city based on data extracted using the Zonal Statistics tool in ArcGIS.

\section{RESULTS}

\section{Overall summary 2010-2020}

The total number conflict events reported for precertification and postcertification countries between 2000 and 2020 is shown in figure 2A,B (data available in online supplemental file 1). Overall, the temporal trends in conflict events across all countries were similar with a marked increase from 2010 onwards.

In the five endemic countries, a total of 18895 conflict events were reported between 2000 and 2020 with the highest numbers in South Sudan $(\mathrm{n}=6986$ from 2011 onwards) representing $37.0 \%$ of the total. In the first decade between 2000 and 2010, a total of 2437 events were reported, which increased 6.8 -fold to 16458 events between 2011 and 2020, with $41.5 \%$ reported in the last 3 years since 2018. In the two countries yet to be certified, a total of 30805 events were reported with the highest 


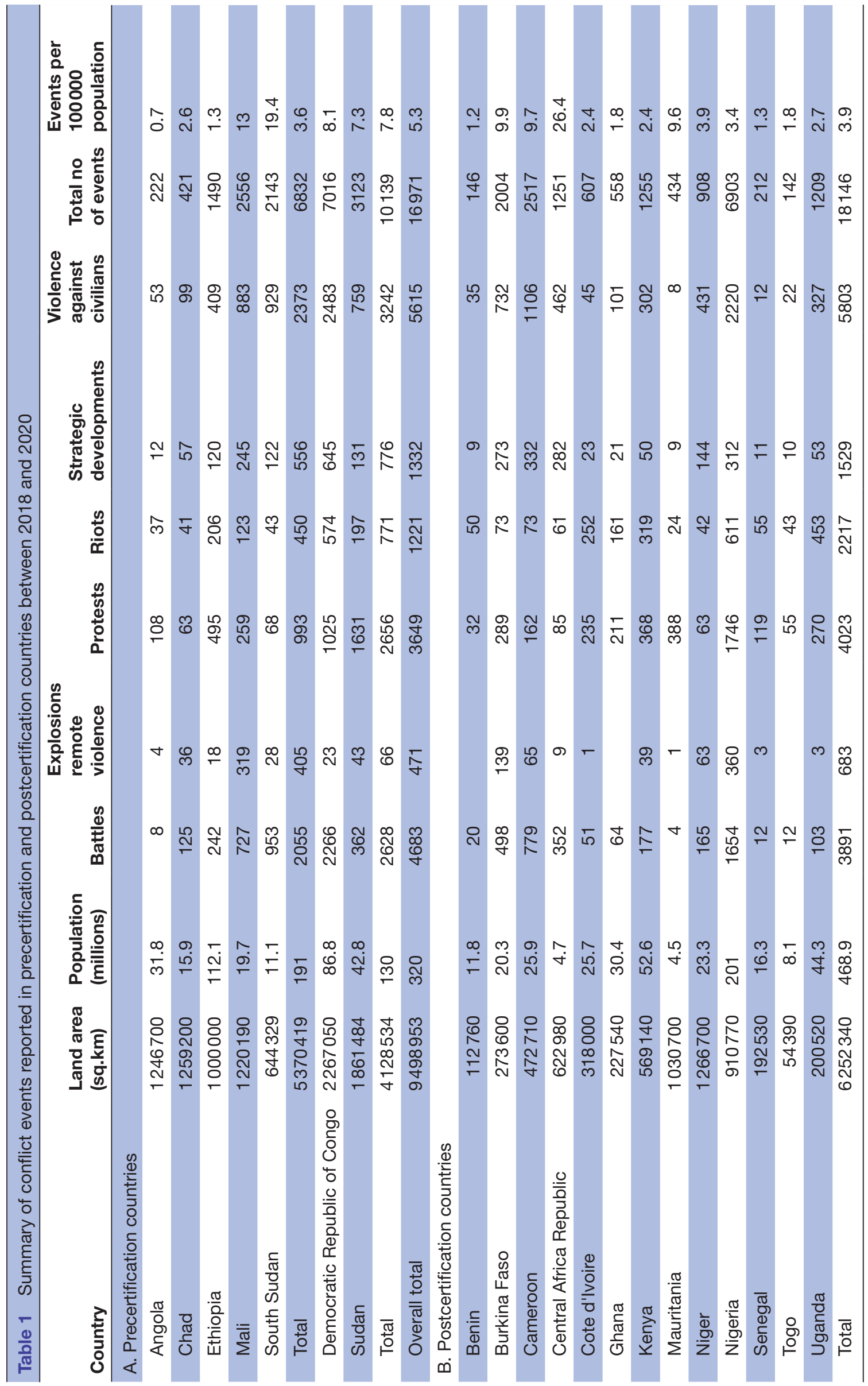



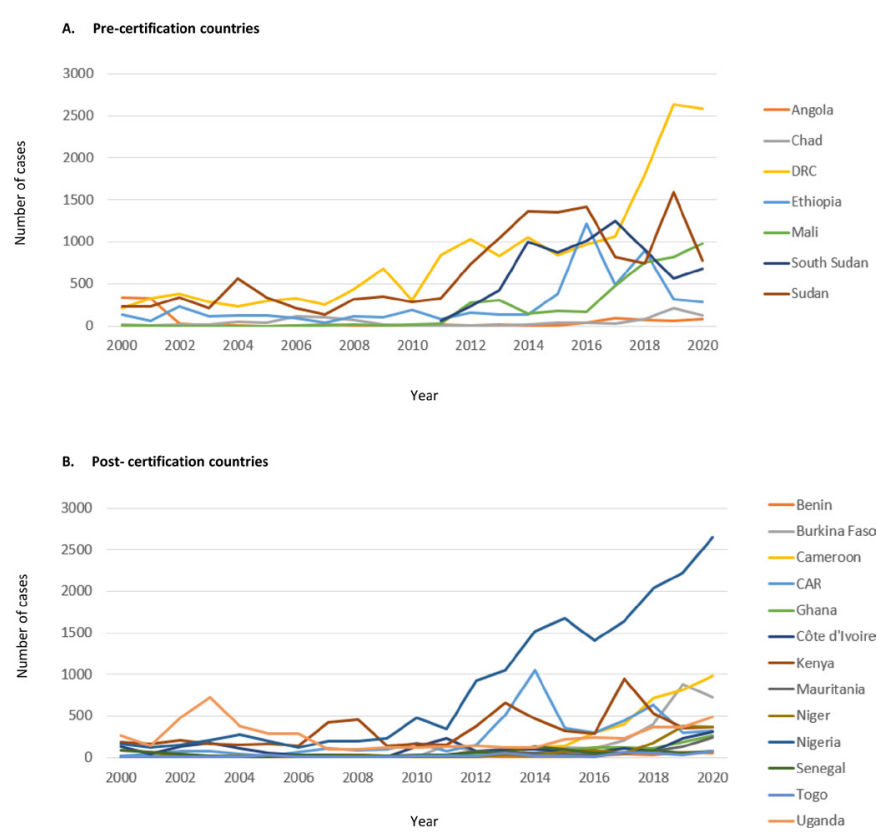

Figure 2 Number of conflict events recorded in precertification and postcertification countries between 2000 and 2020. CAR, Central African Republic; DRC, Democratic Republic of Congo.

numbers in DRC $(\mathrm{n}=17385 ; 56.4 \%)$. Between 2000 and 2010, a total of 6387 events were reported, which increased 3.8-fold to 24418 events between 2011 and 2020 , with $41.5 \%$ reported in the last 3 years.

In the postcertification countries, a total of 48615 events were reported with the highest numbers in Nigeria $(\mathrm{n}=17763)$ representing $36.5 \%$ of the total. In the first decade between 2000 and 2010, the 10244 events were reported, which increased 3.7-fold to 38371 events between 2011 and 2020, with around one-third (37.3\%) reported in the last 3 years.

\section{Summary of conflict events in recent years 2018-2020}

Precertification countries

In the five endemic countries where transmission of $D$. medinensis is ongoing, an overall total of 6832 conflict events were reported between 2018 and 2020 (table 1A and figure 3). The highest numbers and rates per 100000 population were reported in Mali $(\mathrm{n}=2556 ; 13.0$ per 100 000) and South Sudan (n=2143; 19.4 per 100 000). Overall, the most frequently reported events included violence against civilians $(n=2373)$, protests $(n=993)$ and battles ( $\mathrm{n}=2055$ ) with South Sudan reporting the highest number violence incidents against civilians $(39.1 \%$ of total) and battles $(46.4 \%)$ and Ethiopia reporting the highest number of protests $(49.8 \%)$. South Sudan also reported the highest rates of violence against civilians (8.4 per 100000 ), and battles (8.6 per 100000 ), and Mali the highest rates of protests (1.3 per 100000$)$. A summary of the actors reported to be responsible for the highest number and type of conflict events in the high-risk countries is shown in table 2A. For Mali, the actors reported for the most events included Group for Support of Islam
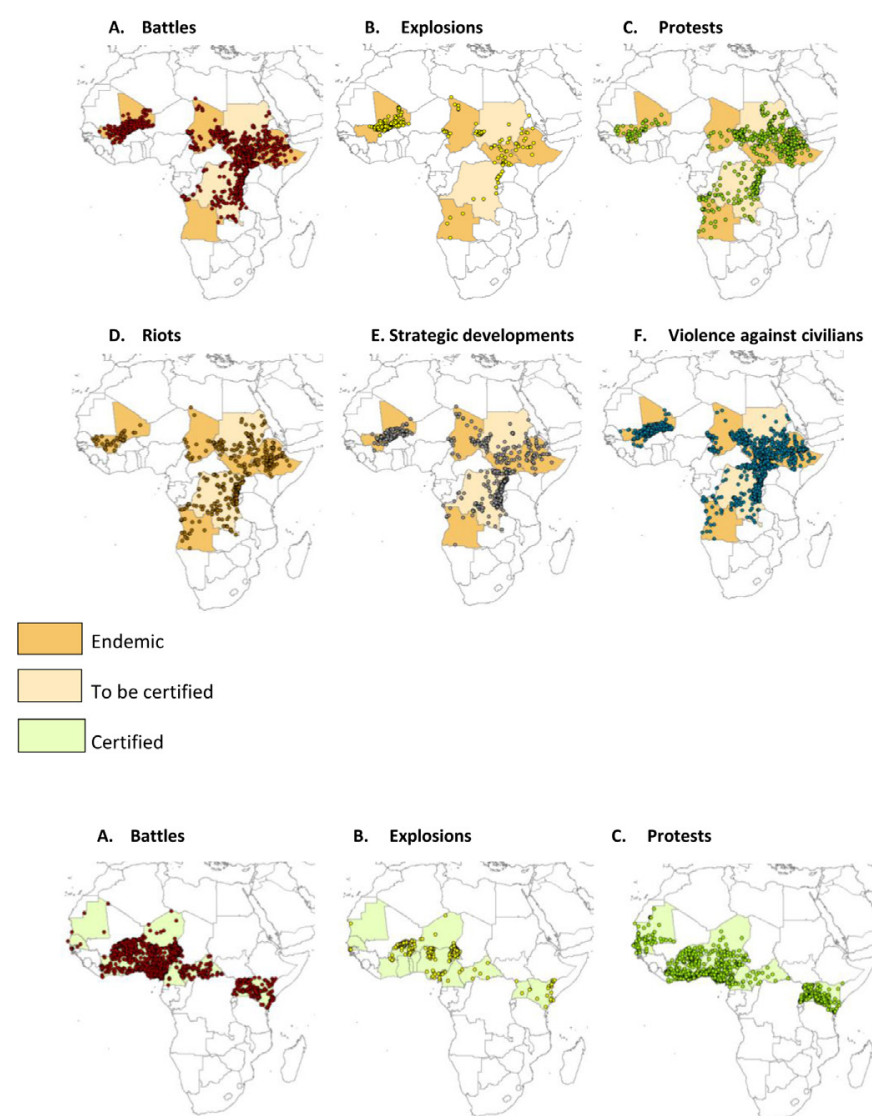

c. Protests
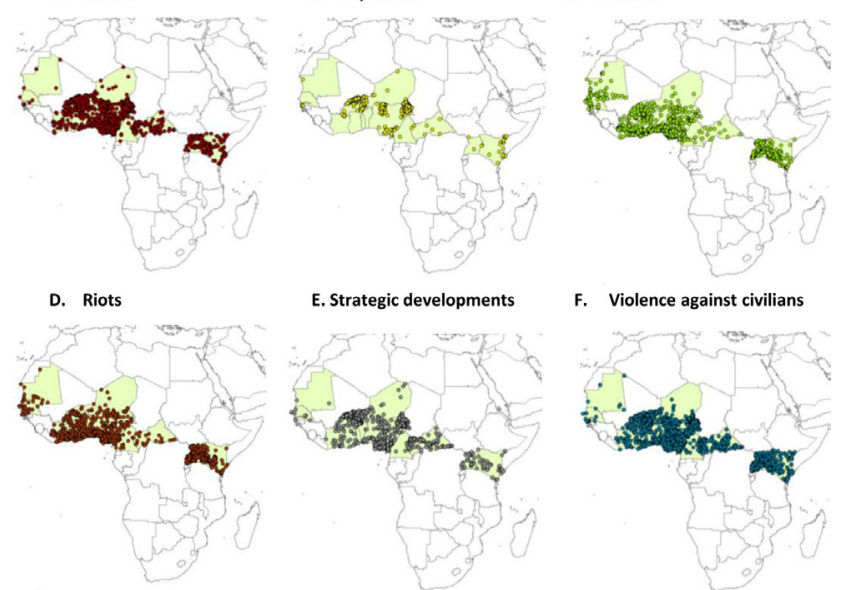

Figure 3 Location of conflict event types between 2018 and 2020 precertification and postcertification countries.

and Muslims (Jama'at Nasr al-Islam wal Muslimin: JNIM) ( $\mathrm{n}=661)$; Unidentified Armed Group (Mali) $(\mathrm{n}=434)$ and Protesters $(n=261)$. For South Sudan, the actors included the Military Forces of South Sudan (2011-) $(n=543)$, Unidentified Armed Group (South Sudan) (n=399) and the Sudan People's Liberation Movement-In Opposition $(\mathrm{n}=157)$.

In DRC and Sudan (two countries where transmission has not been reported recently but required to be certified), a total of 10139 events were reported between 2018 and 2020 (table 1B and figure 3). The highest number and rate per 100000 population were reported in DRC $(\mathrm{n}=7016 ; 8.1$ per 100000$)$. The most frequently reported events included violence against civilians $(n=3242)$ protests $(n=2656)$, and battles $(n=2628)$ with DRC reporting the highest number of these events representing $76.6 \%, 38.6 \%$ and $86.2 \%$ of the total, respectively. The DRC also reported the highest rates of violence against civilians (2.9 per 100000$)$ and battles (2.6 per 100 000 ), and Sudan the highest rates of protests (3.8 per 100 


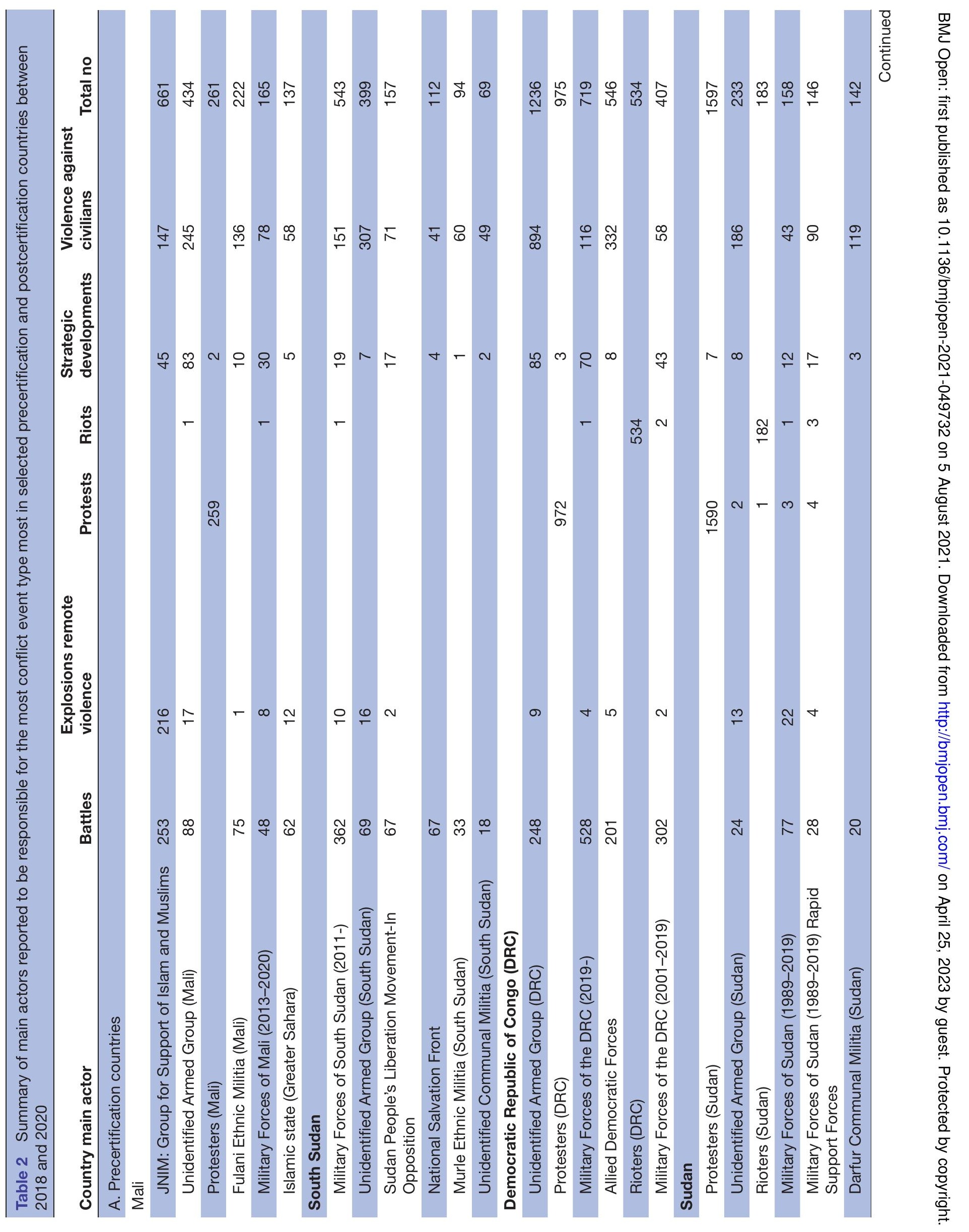




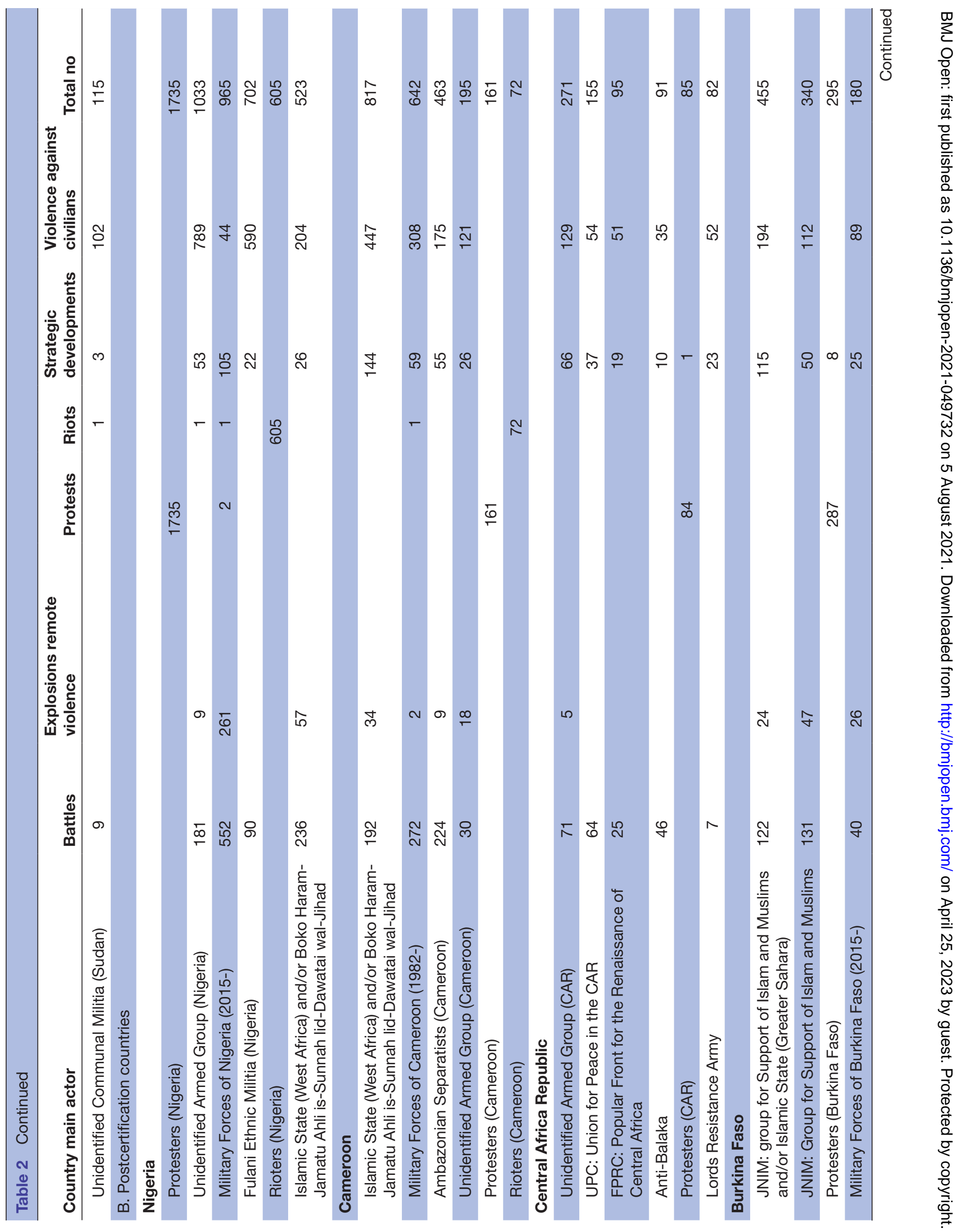


000). A summary of the actors reported to be responsible is shown in table 2A. The main actors associated with the two most reported events in both countries included an Unidentified Armed Group (DRC=1236; Sudan=233) and Protesters $(\mathrm{DRC}=975$; Sudan=1590).

\section{Postcertification countries}

In the postcertification countries, a total of 18146 events (3.9 per 100,000) were reported between 2018 and 2020 (table 1B and figure 3). The highest numbers reported were in Nigeria $(n=6903)$, Cameroon $(n=2517)$, Burkina Faso $(\mathrm{n}=2004)$, and the highest rates in CAR (26.4 per $100,000)$, Burkina Faso $(9.9$ per 100,000$)$ and Cameroon (9.7 per 100000$)$. The most frequently reported events included violence against civilians $(\mathrm{n}=5803)$ protests $(n=4023)$, and battles $(n=3891)$ with Nigeria reporting the highest number of these events representing $38.3 \%$, $43.4 \%$ and $42.5 \%$ of the total, respectively. The CAR reported the highest rates of battles $(7.4$ per 100,000$)$, and violence against civilians (9.7 per 100000$)$ and Mauritania the highest number of protests $(8.5$ per 100000$)$.

A summary of the actors reported to be responsible for the highest number and type of conflict events in the high-risk countries is shown in table 2B. For Nigeria, the actors associated with the two most reported events included Protesters (Nigeria) $(\mathrm{n}=1735)$ and an Unidentified Armed Group $(n=1033)$. For Cameroon, the actors included the Islamic State (West Africa) and/ or Boko Haram-Jamatu Ahli is-Sunnah lid-Dawatai walJihad ( $\mathrm{n}=817)$ and Military Forces of Cameroon (1982-) $(\mathrm{n}=642)$. For CAR, the actors included an Unidentified Armed Group (CAR) $(\mathrm{n}=271)$ and the UPC: Union for Peace in the CAR $(n=155)$. For Burkina Faso, the actors included JNIM: Group for Support of Islam and Muslims and/or Islamic State (Greater Sahara) $(\mathrm{n}=455)$ and JNIM: Group for Support of Islam and Muslims $(n=340)$.

\section{Chad case study}

The capital N'Djamena and six regions reporting Guinea worm human cases and/or animal infections between 2018 and 2020 are shown in figure 4A, B, together with the conflict event types reported in Chad, and the neighbouring precertification country of Sudan and postcertification countries of Cameroon, CAR and Niger.

\section{Guinea worm situation}

Human disease cases were reported in $2018(\mathrm{n}=17), 2019$ $(n=48)$ and $2020(n=13)$. The areas affected included the Chari Baguirmi region, in Bailli (2018; 2019), Bousso (2018; 2019; 2020), Dourbali (2019), Kouno (2019) and Mandelia (2018; 2020) districts; the Moyen Chai region, in Danamadji (2019), Korbal (2018; 2019) Kyabe and Sahr (2018; 2019; 2020) districts; the Salamat region, in Aboudeia (2018; 2019; 2020), Amtiman (2018; 2019) and Haraze (2019); the Tanjile region in Bere district (2018) and the Wadi-Fira region in Matadjana district (2020).

Animal infections, predominately domesticated dog infections were high and reported in 2018 ( $\mathrm{n}=1040)$, 


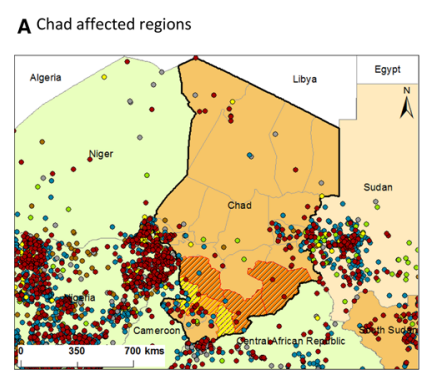

B Chad - close up of affected regions

C Mali

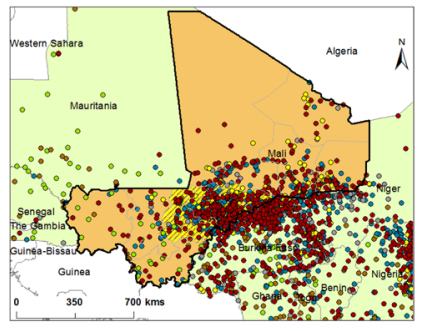

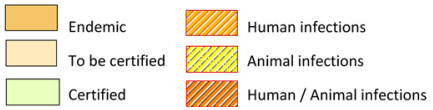

D Mali -close up of affected regions
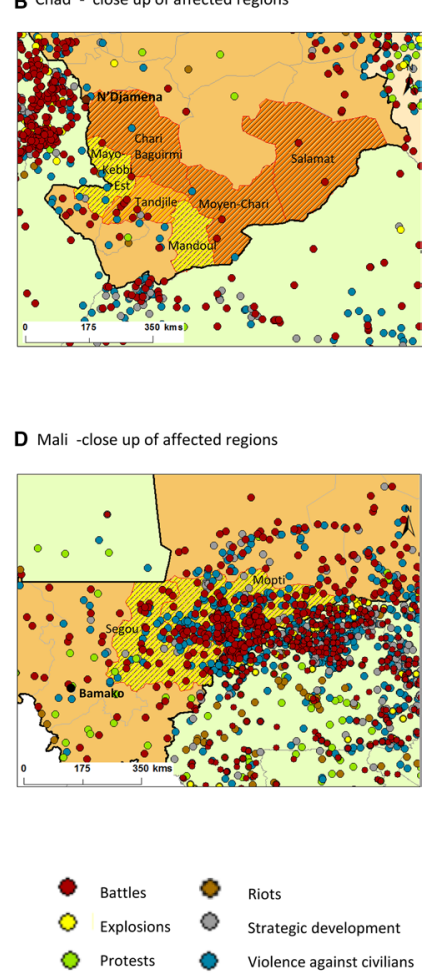

Figure 4 Distribution of guinea worm affected areas in relation to conflict event type between 2018 and 2020 in Chad and Mali. (A) Chad affected regions. (B) Chad-close up of affected regions. (C) Mali affected regions. (D) Maliclose up of affected regions.

$2019(\mathrm{n}=1935)$ and $2020(\mathrm{n}=1464)$. The areas affected included the capital N'Djamena (2018) and the Chari Baguirmi (2018; 2019), Mandoul (2018), Moyen Chai (2018; 2019), Mayo-Kebbi Est $(2018 ; 2019)$ and Salamat (2018; 2019) regions (figure 4B).

\section{Conflict events}

The highest number of conflict events was reported in N'Djamena $(\mathrm{n}=104)$ (table $3 \mathrm{~A})$, were predominately protests (44 events) with protestors reported as the main actors. In the other Guinea worm affected regions, the number of conflict events was lower and ranged from 0 to 13 events in 2018-2020. The main conflict event type in the Chari-Baguirmi region was of violence against civilians (three events) with Military Forces, Police Forces and Moile Communal Militia the main actors; in Moyen-Chari was battles (two events; Unidentified Communal Militia Chad); in Salamat was battles (two events; Nomad and National Guard and Unidentified Communal Militia); in Tanjili was battles (10 events; Fulani Militia, Koutoune Communal Militia; Tandjile Communal militia and Unidentified Armed Group) and in Mayo-Kebbi Est was violence against civilians (four events; Nomad and National Guard, Military Forces, Unidentified Armed Group (Cameroon and Chad)).

\section{Regional access}

The level of access in terms of distance $(\mathrm{kms})$ to the capital N'Djamena and accessibility to a city in hours within Chad and in relation to Guinea worm status and conflict events is shown in table 3A. Of the Guinea worm affected regions, Salamat $(600-700 \mathrm{~km})$ was the furthest from the capital and had the longest estimated time of 10 hours to the nearest city. Of the northerly non-endemic regions, the Lac $(n=88)$, Quadd $(n=57)$ and Tibesti $(n=55)$ had the highest number of conflict events, with Tibesti $(900-1000 \mathrm{~km})$ the furthest distance and had the longest estimated time of 42.1 hours to the nearest city.

\section{Mali case study}

The capital Bamako and two regions reporting Guinea worm animal infections in 2018-2020 are shown in figure $4 \mathrm{C}, \mathrm{D}$, together with the conflict event types reported in Mali, and the neighbouring precertification countries of Burkina Faso, Niger and Mauritania.

\section{Guinea worm situation}

One human case was reported in early 2020-the first human case reported since 2015. Animal infection, predominately domesticated $\mathrm{dog}$ infections were reported in $2018(n=18), 2019(n=8)$ and $2020 \quad(n=9)$. The areas affected included the Mopti region, in Djenne (2018, 2019, 2020) district, and the Segou region in Markal (2018), Tominian, Macina (2018, 2019, 2020) and Baroueli (2020) districts (figure 4D).

\section{Conflict events}

The highest number of conflict events was reported in Mopti region $(\mathrm{n}=1206)$ (table 3B), predominately violence against civilians (561 events) and battles (347 events) with Fulani Ethnic Militia, Groups for Support of Islam and Muslims, Unidentified Armed Group and/ or Military Forces reported as the main actors associated with these events. The main conflict events in the Segou region were battles ( 55 events) and violence against civilians (44 events) with Group for Support of Islam and Muslims reported as the main actors associated with battles and Military Forces of Mali and Dozo Communal Militia main actors for violence against civilians.

\section{Regional access}

The level of access in terms of distance to the capital Bamako and accessibility to a city in hours within Mali and in relation to case status and conflict events is shown in table 3B. Of the Guinea worm affected regions, Mopti was the furthest from the capital Bamako, approximately $500-600 \mathrm{~km}$, and had the longest accessibility time of 4.1 hours to the nearest city. Of the unaffected regions, Gao $(n=503)$, and Tombouctou $(n=264)$ had the highest number of conflict events, with Gao (1000-1100 km) the furthest away from the capital, and Tombouctou the longest estimated time of 62.9 hours to the nearest city.

\section{DISCUSSION}

The GWEP has made remarkable progress since activities began in the late 1980 s with the WHO reporting only tens of human cases in recent years. ${ }^{1527}$ This success has 
Table 3 Summary of guinea worm status, conflict events and regional access for case study countries

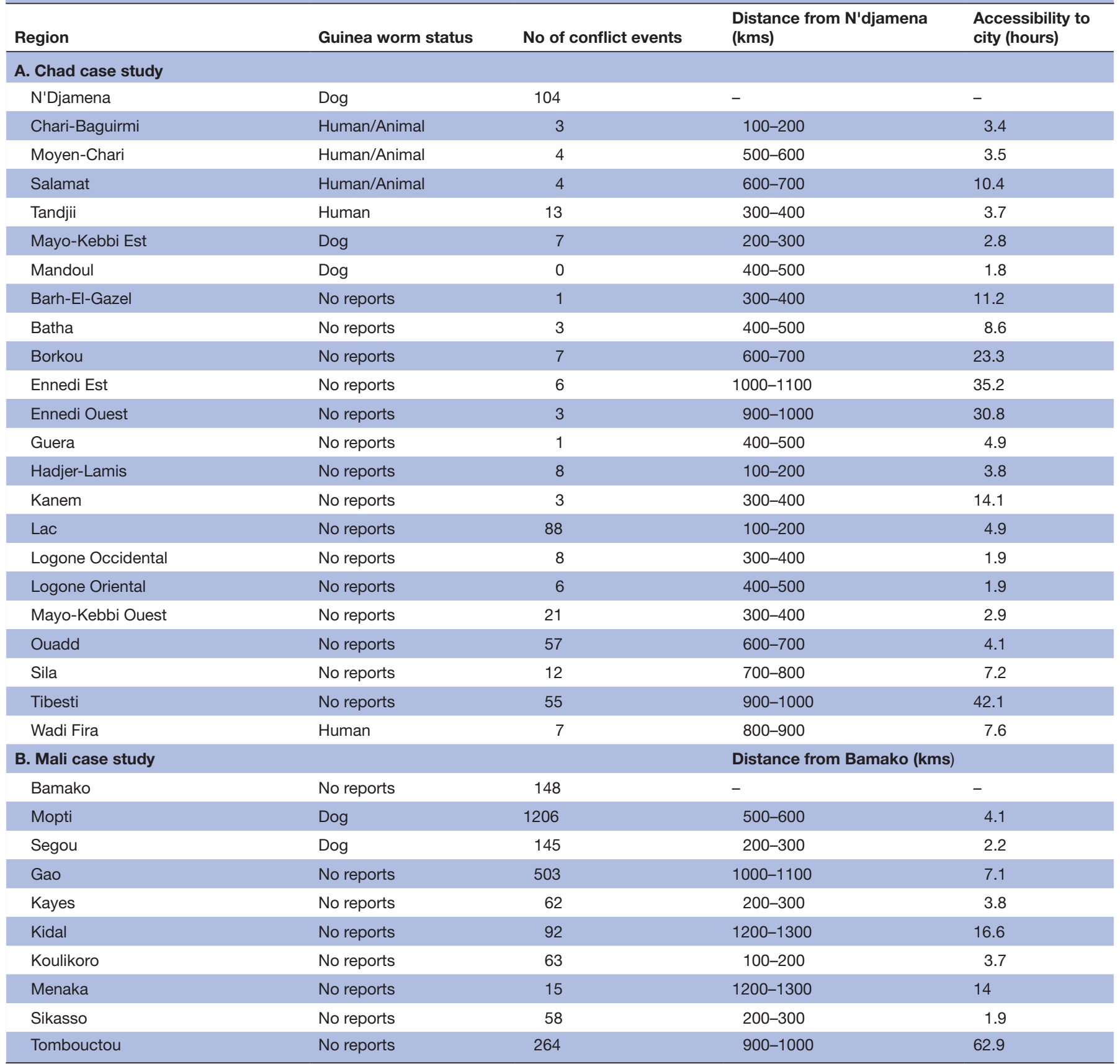

been driven by country commitment, the support from the $\mathrm{WHO}^{2}$ and The Carter Centre ${ }^{3}$ and articulating the fundamental public health interventions to eliminate the transmission-case containment, control of copepods, access to safe drinking water (including filtration), regular reporting and surveillance, and instituting a reward system and the follow-up of rumours. ${ }^{57}$

This paper, however, documents that over the past two decades, the numbers of incidents of conflict and violence have increased dramatically, especially in the last 3 years since 2018. This is not only of concern for endemic countries, but for the two countries yet to be certified, and the 13 countries that were previously endemic for the infection requiring ongoing surveillance. ${ }^{2}$ The Guinea worm community have increasingly recognised that certification will face the challenges of acquiring comprehensive and reliable information in conflictzones and in accessing areas where national governments have limited control. ${ }^{5815} \mathrm{In}$ addition, the porosity of international borders, extensive migration generated by insecurity, intercountry range of many of the actors responsible for violence, and the need for these geographically vast countries to ensure that any Guinea worm case is recognised and reported, highlights the immense challenges programmes face to satisfy the criteria for certifying the absence of transmission and the effectiveness of surveillance. ${ }^{6}$

The characteristics of the situation in areas of West and Central Africa are that there are many groups who are 
responsible for violence at both national and local levels and their motivations are different, even within the same region. ${ }^{28}{ }^{29}$ Understanding how these challenges for the GWEP can be overcome is essential if the country elimination objective and global eradication certification is to be achieved. Providing detailed data, as described in this paper, is necessary so risk assessments can be made to safely operationalise field work, especially in remote locations where access is limited. ${ }^{2031}$ This underscores the value of understanding the spatial and temporal patterns of conflict, identifying hotspots, the actors responsible and their sphere of influence. This information will allow the potential impact of violence on GWEP activities to be assessed consonant with the need to satisfy the robust criteria established by WHO a country to be certified by the ICCDE based on the information in the detailed national report submitted to $\mathrm{WHO}$, and on which the ICT to base their assessments on the likelihood of the country being free of D. medinensis transmission. WHO and the Carter Centre should avail itself of the real-time data available from ACLED to evaluate the challenges and risks to programme staff and in planning certification missions, WHO, should seek to acquire Guinea worm relevant information from areas designated to be of high security risk by country UN Security Advisors as innovative means of acquiring the necessary information for certification will be required.

We have summarised in detail the magnitude, geographical extent and increasing incidence of conflict and violence in those countries where Guinea worm remains a problem for those responsible for ensuring a successful endgame for eradication, which now has a target of 2030 for global certification. ${ }^{4}$ The scale of the challenge can probably best be illustrated by the fact the that the total area of precertification countries is similar to continental USA. $^{25}$ This WHO NTD Road Map target implies that all countries that remain to be certified must have zero cases in humans and animals by $2026 / 2027$ as a minimum of 3 years is required of zero global cases must be reported over the period 2027-2030. This will require intense integrated human and animal surveillance, in countries at present suffering conflict events, with a trend that is regrettably accelerating rather than diminishing. The Chad and Mali case studies highlight the multifaceted epidemiological and conflict situations, the challenging access and safety issues, which will require bespoke risk assessments and innovative strategies to reach certification. A One Health approach including human, animal and environmental components should be considered given the evolving modes transmission, ${ }^{32}{ }^{33}$ taking the cost-effectiveness ${ }^{34}$ and conflict context into account.

The case and conflict event data used in this study are valuable resources to use as a first step in assessing a situation. However, as there are some limitations with using secondary data, it will be important to supplement this information with details from local, reliable sources and trusted partners on the ground, this may help to determine the actors motivations and identify areas that are considered 'secure'. Further, it will be important that local GWEP staff have data management and analytical skills to access, download, examine, summarise and map the data in a meaningful way to inform the programmes. Mapping skills may be developed using user-friendly open sources GIS software such as QGIS (www.qgis.org), which is free to download, has many available online training tutorials available and a range of analytical tool that can produce the same results as presented in this paper.

The methodology and tools we have used in this paper provide a better understanding of the challenges the GWEP faces and are based on the recent studies undertaken to understand and address the risks for other NTD programmes. ${ }^{35}$ These should be more widely promoted not only for Guinea worm, but as a management and risk assessment tool for other research and health programmes working in areas and countries of complex emergencies and insecurity.

Contributors LK-H and DM conceptualised the paper. LK-H accessed data sources, applied analytical methods and produced the maps. Both authors contributed to the data interpretation, writing the first and final version of the manuscript.

Funding The authors have not declared a specific grant for this research from any funding agency in the public, commercial or not-for-profit sectors.

Map disclaimer The inclusion of any map (including the depiction of any boundaries therein), or of any geographic or locational reference, does not imply the expression of any opinion whatsoever on the part of BMJ concerning the legal status of any country, territory, jurisdiction or area or of its authorities. Any such expression remains solely that of the relevant source and is not endorsed by BMJ. Maps are provided without any warranty of any kind, either express or implied.

Competing interests LK-H declares no competing interests. DM is a member of the International Commission for the Certification of Dracunculiasis Eradication.

\section{Patient consent for publication Not required}

Ethics approval No ethical approval was necessary for the paper as it does not involve work on human or animal subjects or experimental work and is based on using analysis of data available in the public domain.

Provenance and peer review Not commissioned; externally peer reviewed.

Data availability statement Data are available in a public, open access repository. All data are available in the paper, online supplemental file and accessible from the public data sources.

Supplemental material This content has been supplied by the author(s). It has not been vetted by BMJ Publishing Group Limited (BMJ) and may not have been peer-reviewed. Any opinions or recommendations discussed are solely those of the author(s) and are not endorsed by BMJ. BMJ disclaims all liability and responsibility arising from any reliance placed on the content. Where the content includes any translated material, BMJ does not warrant the accuracy and reliability of the translations (including but not limited to local regulations, clinical guidelines, terminology, drug names and drug dosages), and is not responsible for any error and/or omissions arising from translation and adaptation or otherwise.

Open access This is an open access article distributed in accordance with the Creative Commons Attribution Non Commercial (CC BY-NC 4.0) license, which permits others to distribute, remix, adapt, build upon this work non-commercially, and license their derivative works on different terms, provided the original work is properly cited, appropriate credit is given, any changes made indicated, and the use is non-commercial. See: http://creativecommons.org/licenses/by-nc/4.0/.

ORCID iD

Louise A Kelly-Hope http://orcid.org/0000-0002-3330-7629

\section{REFERENCES}

1 World Health Organization, World Health Assembly. Resolution WHA39.21: elimination of dracunculiasis 1986. 
2 World Health Organization. Dracunculiasis (Guinea-worm disease), 2020. Available: https://www.who.int/activities/certifying-eradicationof-dracunculiasis

3 The Carter Center. Guinea worm eradication program, 2021. Available: https://www.cartercenter.org/news/publications/health/ index.html [Accessed 10 Jun 2021].

4 World Health Organization. Ending the neglect to attain the sustainable development goals a road map for neglected tropical diseases 2021 - 2030, 2020. Available: https://www.who.int/ neglected_diseases/Revised-Draft-NTD-Roadmap-23Apr2020.pdf? ua $=1$

5 Molyneux DH, Eberhard ML, Cleaveland S, et al. Certifying guinea worm eradication: current challenges. Lancet 2020;396:1857-60.

6 Lemma GW, Müller O, Reñosa MD, et al. Challenges in the last mile of the global guinea worm eradication program. Trop Med Int Health 2020;25:1432-40.

7 Biswas G, Sankara DP, Agua-Agum J, et al. Dracunculiasis (guinea worm disease): eradication without a drug or a vaccine. Philos Trans $R$ Soc Lond B Biol Sci 2013;368:20120146.

8 Hopkins DR, Weiss AJ, Roy SL, et al. Progress toward global eradication of dracunculiasis, January 2019-June 2020. MMWR Morb Mortal Wkly Rep 2020;69:1563-8.

9 World Health Organization. Monthly report on dracunculiasis cases, January - July 2020 Wkly Epidemiol Rec; 2020: 475. https://www. who.int/publications/i/item/who-wer9539-475-476

10 McDonald RA, Wilson-Aggarwal JK, Swan GJF, et al. Ecology of domestic dogs canis familiaris as an emerging reservoir of guinea worm Dracunculus medinensis infection. PLoS Negl Trop Dis 2020;14:e0008170.

11 Molyneux D, Sankara DP. Guinea worm eradication: progress and challenges- should we beware of the dog? PLoS Negl Trop Dis 2017;11:e0005495.

12 Richards RL, Cleveland CA, Hall RJ, et al. Identifying correlates of guinea worm (Dracunculus medinensis) infection in domestic dog populations. PLoS Negl Trop Dis 2020;14:e0008620.

13 Eberhard ML, Ruiz-Tiben E, Hopkins DR, et al. The peculiar epidemiology of dracunculiasis in Chad. Am J Trop Med Hyg 2014;90:61-70.

14 Guagliardo SAJ, Roy SL, Ruiz-Tiben E, et al. Guinea worm in domestic dogs in chad: a description and analysis of surveillance data. PLoS Negl Trop Dis 2020;14:e0008207.

15 World Health Organization. Dracunculiasis eradication: global surveillance summary, 2019 Wkly Epidemiol Rec; 2020: 209-28.

16 Barry M. The tail end of guinea worm - global eradication without a drug or a vaccine. N Engl J Med 2007;356:2561-4.

17 Hopkins DR, Ruiz-Tiben E, Eberhard ML, et al. Dracunculiasis eradication: are we there yet? Am J Trop Med Hyg 2018;99:388-95.

18 Enserink M. Infectious diseases. guinea worm eradication at risk in South Sudanese war. Science 2014;343:236.

19 Gayer M, Legros D, Formenty P, et al. Conflict and emerging infectious diseases. Emerg Infect Dis 2007;13:1625-31.
20 Spiegel PB, Checchi F, Colombo S, et al. Health-Care needs of people affected by conflict: future trends and changing frameworks. Lancet 2010;375:341-5.

21 Leresche E, Truppa C, Martin C, et al. Conducting operational research in humanitarian settings: is there a shared path for humanitarians, National public health authorities and academics? Confl Health 2020;14:1-14.

22 Jacobson J, Bush S, Diseases NT. Neglected tropical diseases, neglected communities, and conflict: how do we leave no one behind? Trends Parasitol 2018;34:175-7.

23 Gardner F. Is Africa overtaking the middle East as the new jihadist battleground?BBC. Available: https://www.bbc.co.uk/news/worldafrica-55147863

24 Al-Lami M. Africa's Sahel becomes latest al-Qaeda-IS battleground, 2020BBC. Available: https://www.bbc.co.uk/news/world-africa52614579

25 World Bank. Indicators, 2021. Available: https://data.worldbank.org/ indicator/ [Accessed 13 Jan 2020].

26 Weiss DJ, Nelson A, Gibson HS, et al. A global map of travel time to cities to assess inequalities in accessibility in 2015. Nature 2018;553:333-6.

27 World Health Organization. Dracunculiasis eradication: global surveillance summary, 2018. Wkly Epidemiol Rec, 2019: 233-52.

28 Clionach R, Linke A, Hegre H. Introducing ACLED: an armed conflict location and event dataset: special data feature. J Peace Res 2010;5:651-60.

29 The armed conflict location \& event data project (ACLED). Available: https://www.acleddata.com/

30 United Nations Office for the Coordination of Humanitarian Affairs $(\mathrm{OCHA})$. The humanitarian data exchange. Available: https://data. humdata.org/ [Accessed 19 Dec 2020].

31 Garber K, Fox C, Abdalla M, et al. Estimating access to health care in Yemen, a complex humanitarian emergency setting: a descriptive applied geospatial analysis. Lancet Glob Health 2020;8:e1435-43

32 Boyce MR, Carlin EP, Schermerhorn J, et al. A one health approach for guinea worm disease control: scope and opportunities. Trop Med Infect Dis 2020;5. doi:10.3390/tropicalmed5040159. [Epub ahead of print: 13 Oct 2020]

33 World Health Organization. Environmental health in emergencies complex emergencies. key policy doc, 2019. Available: https://www. who.int/environmental_health_emergencies/complex_emergencies/ en/

34 Fitzpatrick C, Sankara DP, Agua JF, et al. The cost-effectiveness of an eradication programme in the end game: evidence from guinea worm disease. PLoS Negl Trop Dis 2017;11:e0005922.

35 Kelly-Hope LA, Sanders AM, Harding-Esch E, et al. Complex emergencies and the control and elimination of neglected tropica diseases in Africa: developing a practical approach for implementing safe and effective mapping and intervention strategies. Confl Health 2021;15:18. 